\title{
Neglected causes of post-traumatic stress disorder
}

Patients with psychosis, other delusional states, or autism are also at risk

Chris R Brewin, ${ }^{1}$ [Emeritus Professor in Clinical Psychology], Freya Rumball, ${ }^{2}$ [Clinical Psychologist], Francesca Happé, ${ }^{2}$ [Professor of Cognitive Neuroscience]

${ }^{1}$ Clinical, Educational and Health Psychology, University College London, Gower Street, London WC1E 6BT, UK

${ }^{2}$ Institute of Psychiatry, Psychology, and Neuroscience, King's College London, UK

Correspondence to: c.brewin@ucl.ac.uk

Post-traumatic stress disorder (PTSD) has been defined by successive editions of the American Psychiatric Association's Diagnostic and Statistical Manual of Mental Disorders (most recently DSM-5). The diagnosis requires an objectively traumatic event that involves exposure to "death, threatened death, actual or threatened serious injury, or actual or threatened sexual violence." This focus on objective event characteristics maintains PTSD as a response to extreme rather than everyday stress, but it overlooks mounting evidence that subjective responses to traumatic events predict PTSD just as or more strongly. ${ }^{1}$ Groups of patients who are at risk of developing PTSD might be overlooked because the triggering event is subjectively rather than objectively traumatic. We describe three such groups here, but there are undoubtedly others.

Traumatic events, both objective and subjective, are common in the lives of patients with psychosis. Experiences, such as being forcibly sedated or admitted to hospital during an acute episode, can be terrifying to someone who cannot understand fully what is happening or appreciate the motives of those involved. Hallucinations and delusions can also be extremely frightening and can be experienced in the same way as an actual threat of serious physical injury. People with the delusion that others are trying to kill them, for example, might experience PTSD symptoms such as intrusive memories, flashbacks, and nightmares related to episodes when they thought that they were about to be attacked. That the experience of psychosis itself can be traumatic has been known for at least 30 years, ${ }^{2}$ and in recognition of this an informal category of "psychosis related PTSD" has been proposed by researchers. ${ }^{34}$

Similar considerations apply to people treated in intensive care units, who experience high rates of post-traumatic symptoms after discharge. ${ }^{5}$ Although these symptoms occur in the context of a genuine threat to life, their content is frequently unrelated to the objective threat but rather to delusions and hallucinations induced by prescribed drugs. 
In detailed interviews, patients have reported delusions such as being poisoned, assaulted, tortured, kidnapped, threatened with death, or put on trial. Elements of hospital care such as injections, blood tests, and endotracheal tubes have merged with hallucinatory content to form terrifying delusional narratives. ${ }^{6}$ As with psychosis, post-traumatic symptoms arising from these experiences would not traditionally lead to a diagnosis of PTSD because the DSM criteria assume that affected individuals have the mental capacity to evaluate events objectively.

Finally, people with autism spectrum disorder (ASD), a neurodevelopmental condition associated with atypical processing of the social and sensory world, often show intense threat responses to apparently harmless situations, such as changes in routine, social situations, or sensory stimuli. ASD may be associated with unique experiences and perceptions of trauma. ${ }^{7-}$ 9

Reduced emotional coping skills place people with ASD at high risk of mood and anxiety disorders after exposure to stressors such as social misperceptions, prevention of repetitive or stereotyped behaviours, and aversive sensory experiences. ${ }^{10}$ Among people with ASD, in appears these atypical stressors may be associated with PTSD symptomatology as often as objectively traumatic events (Rumball, 2018). If so, rates of PTSD currently reported among children and adolescents with ASD (0-5.9\%, mean 2.85\%) are an underestimate. ${ }^{11}$

Effective treatment of these neglected groups requires the same trauma-focussed therapies that are recommended for PTSD after objectively traumatic events. ${ }^{11}{ }^{12}$ Where DSM-5 is used, failure to diagnose PTSD because of the nature of the triggering event might result in the denial of treatment. We therefore recommend adding an "altered perception" subtype to existing PTSD criteria in a future version of the DSM. This would preserve PTSD as a response to extreme stress while recognising that, for those with atypical perceptual or cognitive processing (whether temporary or life long), intense fear or horror might be provoked by events not traditionally considered traumatic.

Such a subtype would not apply where a neurotypical individual simply reported an exaggerated perception of threat, for example someone with a phobia of spiders who felt extreme fear on seeing a small spider.

In contrast to DSM-5, the World Health Organization's international classification of diseases (ICD-11) will allow clinicians to make a diagnosis of PTSD based on their assessment of whether an event involves "exposure to an extremely threatening or horrific event or series of events," 13 thus allowing flexibility over whether the threat is subjective or objective. Whichever system is in use, clinicians must be alert to the possibility of PTSD in 
patients with psychosis, other delusional states, or ASD who have experienced subjectively terrifying events. They should not be dissuaded from referring symptomatic patients for treatment simply because current diagnostic rules neglect these patients' altered perceptual experiences.

Copyright/License for Publication: The Corresponding Author has the right to grant on behalf of all authors and does grant on behalf of all authors, a worldwide licence to the Publishers and its licensees in perpetuity, in all forms, formats and media (whether known now or created in the future), to i) publish, reproduce, distribute, display and store the Contribution, ii) translate the Contribution into other languages, create adaptations, reprints, include within collections and create summaries, extracts and/or, abstracts of the Contribution, iii) create any other derivative work(s) based on the Contribution, iv) to exploit all subsidiary rights in the Contribution, v) the inclusion of electronic links from the Contribution to third party material where-ever it may be located; and, vi) licence any third party to do any or all of the above.

Competing Interests: The BMJ has judged that there are no disqualifying financial ties to commercial companies. The authors declare the following other interests: CB was an unpaid adviser to the American Psychiatric Association's DSM-5 subworking group on trauma and dissociation and was an unpaid member of the working group on classification of stress related disorders for the World Health Organization's International Advisory Group for the Revision of ICD-10 Mental and Behavioural Disorders. The views expressed in this article are those of the authors and do not represent the official policies or positions of the International Advisory Group or WHO. Further details of The BMJ's policy on financial interests is here https://www.bmj.com/sites/default/files/attachments/resources/2016/03/16current-bmj-education-coi-form.pdf

Provenance and peer review: Not commissioned, peer reviewed <jrn>1 Ozer EJ, Best SR, Lipsey TL, Weiss DS. Predictors of posttraumatic stress disorder and symptoms in adults: a meta-analysis. Psychol Bull 2003;129:52-73. . PubMed doi:10.1037/0033-2909.129.1.52</jrn>

$<$ jrn>2 Shaner A, Eth S. Can schizophrenia cause posttraumatic stress disorder? Am J Psychother 1989;43:588-97. PubMed doi:10.1176/appi.psychotherapy.1989.43.4.588 </jrn> $<$ jrn>3 Fornells-Ambrojo M, Gracie A, Brewin CR, Hardy A. Narrowing the focus on the assessment of psychosis-related PTSD: a methodologically orientated systematic review. Eur J Psychotraumatol 2016;7:32095. . PubMed doi:10.3402/ejpt.v7.32095</jrn> $<$ jrn $>4$ Berry K, Ford S, Jellicoe-Jones L, Haddock G. PTSD symptoms associated with the experiences of psychosis and hospitalisation: a review of the literature. Clin Psychol Rev 2013;33:526-38. . PubMed doi:10.1016/j.cpr.2013.01.011</jrn> $<\mathrm{jrn}>5$ Wade DM, Howell DC, Weinman JA, et al. Investigating risk factors for psychological morbidity three months after intensive care: a prospective cohort study. Crit Care 2012;16:R192. . PubMed doi:10.1186/cc11677</jrn>

<jrn>6 Wade DM, Brewin CR, Howell DCJ, White E, Mythen MG, Weinman JA. Intrusive memories of hallucinations and delusions in traumatized intensive care patients: An interview study. Br J Health Psychol 2015;20:613-31 . PubMed doi:10.1111/bjhp.12109</jrn> <jrn> 7 Haruvi-Lamdan N, Horesh D, Golan O. PTSD and autism spectrum disorder: Comorbidity, gaps in research, and potential shared mechanisms. Psychol Trauma 2018;10:2909. . PubMed doi:10.1037/tra0000298</jrn> 
<jrn>8 Kerns CM, Newschaffer CJ, Berkowitz SJ. Traumatic childhood events and autism spectrum disorder. J Autism Dev Disord 2015;45:3475-86. PubMed doi:10.1007/s10803-015$\underline{2392-\mathrm{y}</ j \mathrm{jn}>}$

$<$ jrn $>9$ Peterson JL, Earl RK, Fox EA, et al. Trauma and autism spectrum disorder: Review, proposed treatment adaptations and future directions. J Child Adolesc Trauma 2019; doi:10.1007/s40653-019-00253-5 . </jrn>

$<$ jrn $>10 \quad$ Wood JJ, Gadow KD. Exploring the nature and function of anxiety in youth with autism spectrum disorders. Clin Psychol 2010;17:281-92. doi:10.1111/j.14682850.2010.01220.x.</jrn>

$<\mathrm{jrn}>11 \quad$ Rumball F. A systematic review of the assessment and treatment of posttraumatic stress disorder in individuals with autism spectrum disorders. Rev J Autism Dev Disord 2018, doi:10.1007/s40489-018-0133-9. </jrn>

$<$ jrn>12 van den Berg DPG, de Bont PAJM, van der Vleugel BM, et al. Prolonged exposure vs eye movement desensitization and reprocessing vs waiting list for posttraumatic stress disorder in patients with a psychotic disorder: a randomized clinical trial. JAMA Psychiatry 2015;72:259-67. PubMed doi:10.1001/jamapsychiatry.2014.2637</jrn> $<$ jrn>13 Maercker A, Brewin CR, Bryant RA, et al. Diagnosis and classification of disorders specifically associated with stress: proposals for ICD-11. World Psychiatry 2013;12:198-206. PubMed doi:10.1002/wps.20057</jrn>

Rumball, F. (2018) . Traumatic Life Events and the Mechanisms of Posttraumatic Stress Disorder Development in Adults with Autism Spectrum Disorders. Unpublished DClinPsy thesis, King's College London. 